\title{
Real Estate Agent Target Marketing: Are Buyers Drawn Towards Particular Real Estate Agents?
}

\author{
Aaron Arndt, David M. Harrison, Mark A. Lane, Michael J. Seiler, and Vicky L. \\ Seiler
}

\section{Abstract}

We investigate whether customers' overall impression of online property listings can be influenced by the real estate agent, and whether this influence depends on the customer's demographic characteristics. A sample of 1,594 potential homebuyers took an online audio/visual tour of a typically priced home in their area. Subjects were shown one of eight conditions in which we varied agent gender (male/female), agent attractiveness (attractive/less attractive), and pathos (used/not used). The results show that segments of customers are drawn to different real estate agents, but contrary to our expectations, customers were not necessarily drawn to similar agents or more attractive ones.

New real estate agents are often advised to target a specific niche, similar to the concept of target marketing for firms. Yet, while there is abundant research on how larger firms can identify and target consumer segments (Smith and Cooper-Martin, 1997; Lovelock, 1983), there are few actionable suggestions for a real estate agent to accomplish this same task. In order to attract buyers, real estate agents often post their pictures and contact information, along with property listings. To that end, this research investigates how real estate agent information included in online listings can attract customers, rather than examining the later stages of the buying process, in which personal selling occurs. Once a customer has contacted a real estate agent, the agent should use best practices in professional selling, such as customer orientation and adaptive selling (Franke and Park, 2006), in which each buyer is treated as an individual. Nevertheless, it is still important to understand the segmentation process so that agents can attract customers.

There is an opportunity cost to viewing houses (Pryce and Oates, 2008). So, it is likely that people will only meet with an agent to view a property if they have a sufficiently favorable overall impression of that property's listing. According to the "halo effect," peoples' evaluations are often influenced by salient but irrelevant attributes (Johnson and Vidulich, 1956; Lucker, Beane, and Helmreich, 1981). We opine that real estate agent characteristics influence customers' overall property evaluations. However, these individuals have diverse backgrounds and preferences; thus, two people could form very different attitudes towards the same salesperson. For example, the theory of homophily posits that people prefer others who are like them (McPherson, Smith-Lovin, and Cook, 2001). If homophily holds, people should prefer similar agents. Extending this logic using the halo effect, people might even evaluate properties more favorably if represented by similar agents. Accordingly, our first goal is to examine whether demographic similarity between an agent and a customer can influence the customer evaluations of a property. 
In addition to homophily, more attractive agents might have advantages over less attractive agents. Salter, Mixon, and King (2012) find that physically attractive real estate agents have higher wages and are more productive than less attractive agents. However, it is not clear whether it is better to emphasize attractiveness or similarity when dealing with customers. Therefore, our second goal is to examine the effect of agent attractiveness.

Agent appearance also influences customer attitudes towards the agent's communications. How property features are presented can influence the selling price and speed of sale (Springer, 1996; Goodwin, Waller, and Weeks, 2014); thus, agents might use different approaches to presenting information about a property. While some agents use a purely factual approach to communications, other agents actively attempt to influence the market by using pathos, rhetorical language intended to make buyers more favorably inclined towards a property (Smith, Munro, and Christie, 2006). Certain buyers may be more accepting of pathos from certain agents than from others. According to the persuasion knowledge model (PKM), people evaluate communications from persuasive agents based, in part, on agent knowledge (Friestad and Wright, 1994). When a persuasive message is deemed inappropriate, customers reject the message. When meeting an agent for the first time, customers have little agent knowledge beyond stereotypical factors, such as physical appearance. Hence, an agent's appearance can shape whether persuasive messages are accepted or rejected. For example, if customers feel attractive agents are more trustworthy than less attractive agents, then they may be less guarded towards persuasive communications from attractive agents. Hence, pathos is more likely to be effective. Therefore, our third goal is to examine whether pathos is more likely to influence customers' perception of a property based on similarity and level of attractiveness.

To examine the three research goals, we conducted a controlled experiment in which 1,594 potential homebuyers took a web-based audio/visual tour of a typically priced home in their area. Subjects were shown one of eight conditions in which we varied agent gender (male/female), agent attractiveness (attractive/less attractive), and pathos (used/not used). We investigate the influence of customer characteristics on property impression for each condition separately rather than differences between agent conditions; therefore, we look at within-condition influences to see which customers are drawn to each particular agent.

\section{Theoretical Development}

\section{The Halo Effect of Agent Characteristics}

There is a substantial body of literature on the halo effect, a judgment bias in which peoples' evaluations are influenced by salient but irrelevant attributes (Johnson and Vidulich, 1956; Lucker, Beane, and Helmreich, 1981). Interestingly, people are often completely unaware when they are being influenced by a halo effect and defend their judgment even when the bias is pointed out to them (Nisbett and Wilson, 1977). Homophily, agent attractiveness, and pathos are irrelevant to the evaluation of a particular property; hence, they should not influence a customer's impression of a property. Yet, 
we argue that pictures of the real estate agent and pathos used in a property listing can result in a halo effect that does in fact influence someone's overall impression of a property.

\section{Agent Characteristics: Homophily}

Homophily is "the degree to which pairs of individuals are similar in terms of certain attributes such as sex, education and social status"' (Brown and Reingen, 1987, p. 354). According to homophily theory, people tend to connect with others who are similar to themselves in some characteristics such as age, gender, race, education, values, etc. (McPherson, Smith-Lovin, and Cook, 2001). Homophily has been discussed since antiquity; for example, Aristotle observed that people "love those who are like themselves" (Aristotle translation in 1934, p. 1371) and Plato noted "similarity begets friendship" (Plato translation in 1968, p. 837). Although this similarity-attraction relation can stem from many different types of characteristics, often the strongest bonds develop from fixed demographic characteristics such race, ethnicity, gender, or age (McPherson, Smith-Lovin, and Cook, 2001).

The influence of homophily has been shown in business transactions as well. For example, Ravina (2011) finds that black lenders are more likely to lend to black borrowers. Moreover, these borrowers were less likely to default on the loan. And while white lenders were not more likely to lend to white borrowers, they did offer loans at a lower interest rate. Eckel and Wilson (2003) found less trust when going across black and white racial lines. Therefore, ceteris paribus, we expect that customers would prefer to work with real estate agents who share similar characteristics.

\section{Agent Characteristic: Physical Attractiveness}

Physical attractiveness is also an important characteristic. Abundant research shows that attractive people have an advantage over less attractive individuals (e.g., Bower and Landreth, 2001; Cialdini, 2009). In the context of real estate, Salter, Mixon, and King (2012) find that physically attractive real estate agents have higher wages and productivity than less attractive agents. Ravina (2011) examined unsecured personal loans to see if qualitative borrower characteristics influence the decision to loan money, as well as the characteristics of the resulting loan. The author finds that, holding borrower risk constant, attractive borrowers are more likely to qualify for loans and pay fewer basis points than average-looking borrowers. Consistent with the better treatment results of Mobius and Rosenblat (2006) and Andreoni and Petrie (2008), Ravina (2011) finds that the bettertreated, attractive borrowers actually have substantially lower loan performance. Hence, attractive real estate agents should generally draw more buyers.

\section{Agent Strategy: Use of Pathos}

In addition to the basic factual characteristics of a home (e.g., square footage, number of bedrooms and bathrooms, etc.), the Multiple Listing Service (MLS) provides a place for agents to include a qualitative description of the property. Some of this information is factual in nature such as being recently painted, having a new roof, or being located near a lake. However, qualitative descriptions can also include pathos such as "good buy," 
"motivated seller," "good location," and "well-maintained," in order to influence the perception of potential buyers. Interestingly, Haag, Rutherford, and Thomson (2000) find that properties with pathos in the description sell for less, perhaps because agents are more inclined to use pathos to promote inferior properties perceived to be inferior or where the seller is motivated to sell quickly. Similarly, Springer (1996) finds that postings that indicate a seller is motivated to sell quickly have a lower selling price. On the other hand, Goodwin, Waller, and Weeks (2014) find that including a comprehensive listing of property characteristics and positive opinions increased the selling price of a home.

Friestad and Wright (1994) propose that people actively evaluate persuasive messages to determine the appropriateness of the message and the goals of the persuader. Because impressions of a person are long lasting (Evans, Kleine, Landry, and Crosby, 2000; Schneider, 2005), we argue that message may be interpreted differently based on first impressions of the persuader. Hence, the picture of the real estate agent could influence how customers interpret pathos in a property listing. Therefore, we examine the interaction between homophily and agent attractiveness on the effectiveness of pathos.

\section{Study Design}

The experimental design uses eight unique variations of a web-based tour of the same home, varying real estate agent physical attractiveness (attractive vs. less attractive), gender (male vs. female), and pathos (no pathos vs. pathos). Real estate agent physical attractiveness is manipulated using before and after makeover photos for both a male and female real estate agent. The models for the real estate agents include a Caucasian man and woman who are as similar in appearance as possible, including factors such as age, genetic make-up, hair and eye color, etc. The photographs were positioned to ensure that facial features are the same size in all of the images. Consistent with Patzer (1985) and Morrow (1990), we use a photo of a person's face to measure physical attractiveness.

During the home tour, subjects listened to a verbal description of the property. To manipulate the use of pathos in the audio presentation, we began by recording the "pathos" condition spoken with a female voice, in which the description of the property was enhanced with superlatives. Then we create the "no pathos" condition by digitally deleting all the extraneous superlatives so that subjects heard only objective, quantifiable facts about the property. The male versions of the conditions were developed by digitally altering the sound files to create a male's voice. ${ }^{1}$ We then matched the gender of the audio files with the corresponding photographs to create the eight conditions.

The overall impression of the home was measured on a nine-point Likert scale. We asked subjects: "What is your overall impression of this house?" (extremely favorable $=9 /$ not favorable at all $=1$ ). They were then asked a series of demographic questions including gender $($ female $=0$; male $=1$ ), age, marital status ( ingle $=0$, married $=1$ ), level of education (did not receive a college degree $=0$, received a college degree $=1$ ), sexual orientation (heterosexual $=0$, homosexual $=1$ ), and race/ethnicity, which was converted to dummy variables Caucasian (no $=0$, yes $=1$ ), Black (no $=0$, yes $=1$ ), Asian (no $=0$, yes $=1$ ), and Hispanic (no $=0$, yes $=1$ ). Subjects were also asked questions germane to their typical home-buying behaviors including their net worth, the 
number of homes they have purchased in their lifetime, and whether they tend to buy a cheaper or more expensive home (measured on a 9-point scale, with $1=$ far less expensive and $9=$ far more expensive). The latter question was transformed into two separate variables, tendency to buy a cheaper home and tendency to buy a more expensive home, so that effects would be linear rather than curvilinear.

Current and prospective owner-occupant homeowners from across the United States were used for the collection of all data employed in this experiment. We accessed MTurk for the sample, restricting the survey to current (and currently searching) homeowners, with a past approval rating on previous MTurk assignments of greater than $95 \%$. To ensure subjects were listening to the audio, we provided an audible code after the tour that had to be entered into the survey correctly. Then, to ensure they read questions carefully, several questions asked them to enter a specific number. If any of these data screens were not answered correctly, the response was eliminated from the final sample. Furthermore, several people failed to fully complete the experiment. The number of participants rejected was approximately 5\%, leaving a final sample size of 1,594 complete and valid responses.

\section{Results}

\section{Manipulation Check}

To begin, we checked the manipulation of attractiveness. We asked subjects to rate the attractiveness of the agent using a 9-point scale with 1 being "not at all physically attractive" and 9 being "very much physically attractive." The mean attractiveness was significantly different between the more attractive and less attractive conditions ( $\mathrm{F}=$ $1129.86, p<.01$, mean ${ }_{\text {more attractive }}=6.01$, mean $\left._{\text {less attractive }}=3.09\right)$. Thus, the manipulation of attractiveness was successful. Interestingly, when comparing rating scores across respondent and agent gender, we found that respondent males were hesitant to rate the attractive male agent as being too attractive, but both genders had no problem rating the attractive female agent as such. However, male respondents did slightly rate the less attractive male agent as being not as bad looking as the female respondents reported.

\section{Main Analysis}

Unlike other experimental designs that focus on between-group differences, our primary interest is determining which customers are influenced by which particular agent/use of pathos. Hence, although we briefly look at between-group effects, we focus on withingroup differences. In order to identify influential demographic characteristics for each of the eight categories, we used OLS regression. Independent variables included respondent gender, age, marital status, college degree achievement, sexual orientation, four dummy variables for race/ethnicity (Caucasian, Black, Asian, and Hispanic), net worth, number of previous homes purchased, tendency to buy cheaper homes and tendency to buy more expensive homes. The purpose of this research is to identify significant demographic characteristics; however, the statistical power to detect effects could be masked by insignificant variables. Accordingly, we used "backwards" variable entry, where all variables are entered into the equation at the same time and then non-significant variables 
are eliminated one by one until only significant variables remain. Exhibit 1 presents the significant variables in each regression model.

After identifying the influential variables for each model, further analysis was conducted to better understand how each demographic characteristic specifically influenced home impression. When there were only two categories for a demographic variable, an independent samples $t$-test was used. When there were more than two categories, ANOVA and post hoc tests were used. In both cases, a Levene statistic was first calculated to determine if variances could be assumed equal. Exhibit 2 shows the mean scores for the overall home impression for each of the eight categories (containing each combination of the three real estate agent characteristics). No interaction effects between demographic variables are significant so only the main effects are presented.

For between-group effects, what stands out the most in Exhibit 2 is the statistically significantly higher rating that results from the attractive female agent who uses pathos. Not only is this category significantly higher than others, but it is also specifically significantly higher than Category 2-the results associated with the same attractive female who did not employ pathos. Hence, buyers reported the highest grand mean of overall impression of the house when presented with the attractive female agent using pathos. This supports our central hypothesis that agent characteristics and persuasive tactics do have a halo effect on the buyer's overall home impression. However, not all real estate agents are attractive females, and not all attractive female agents believe in using pathos. Furthermore, certain buyer groups may prefer other agent characteristics or not using pathos. Hence, for the remainder of the results, we shift our attention to within-group differences for each agent, shown in Exhibit 2.

The Effect of Homophily. Above we proposed that customers should prefer agents who are like them. If that were true, then they should prefer agents of the same gender, and Caucasian customers should be more influenced than other races because the agent is Caucasian. However, the results did not show this to be the case. Gender only influenced impression for one agent, the less attractive female not using pathos, and males were more influenced than females. Similarly, Caucasian subjects were not more influenced by agents than non-Caucasian subjects. In fact, they were less influenced by the less attractive male who was not using pathos than other subjects. This means that homophily does not cause a halo effect on property impressions. Therefore, agents will not necessarily attract more customers with the same demographic characteristics.

The Effect of Attractiveness. According to previously discussed theory, agent attractiveness should increase a subject's overall home impression for all of the groups. Contrary to this supposition, both the highest and lowest overall impressions were generated by the attractive agents, the highest impression elicited by the attractive female using pathos, and the two lowest being the attractive male agent using pathos and the attractive female agent not using pathos. Indeed, as hypothesized, the specific influence of agent attractiveness varied on the subject segment and the use of pathos. For example, subjects without a college degree were most influenced by the attractive female not using pathos. Conversely, the highest overall impression of any group was from Black subjects who were shown the unattractive male agent using pathos. Therefore, agents who are attractive will not necessary entice more customers to contact them than less attractive agents. 
Exhibit 1. Regression Models

\begin{tabular}{|c|c|c|c|c|c|c|c|c|c|}
\hline \multirow{3}{*}{$\begin{array}{l}\text { Agent gender } \\
\text { Attractiveness }\end{array}$} & Cat 1 & Cat 2 & Cat 3 & Cat 4 & Cat 5 & Cat 6 & Cat 7 & Cat 8 & Combined \\
\hline & \multicolumn{2}{|l|}{$\overline{\text { Female }}$} & \multicolumn{2}{|l|}{ Male } & \multicolumn{2}{|l|}{ Female } & \multicolumn{2}{|l|}{ Male } & \\
\hline & Low & High & Low & High & Low & High & Low & High & \\
\hline Used pathos & No & No & No & No & Yes & Yes & Yes & Yes & \\
\hline Gender & $0.13^{*}$ & - & - & - & - & - & - & - & - \\
\hline Age & - & - & - & - & - & $0.12 *$ & - & - & - \\
\hline Married & - & - & - & $0.15^{* *}$ & - & - & - & - & $0.10 * * *$ \\
\hline College & - & $-0.22 * * *$ & - & - & - & - & - & $-0.14^{*}$ & - \\
\hline Sexual Or & - & - & - & - & - & $0.12 *$ & - & - & - \\
\hline Caucasian & - & - & $0.56^{*}$ & - & - & $-0.14^{*}$ & - & - & - \\
\hline Black & - & - & $0.39 * *$ & - & - & $-0.22 * * *$ & - & - & - \\
\hline Asian & - & $-0.12^{*}$ & $0.49 * *$ & - & $-0.18 * *$ & - & - & - & - \\
\hline Hispanic & - & - & $0.43 * *$ & - & - & - & - & - & - \\
\hline Net Worth & - & - & - & - & - & - & - & $0.12 *$ & \\
\hline \# home purchases & $-0.15^{* *}$ & - & - & - & - & - & - & - & - \\
\hline Cheaper & - & $-0.17^{* *}$ & - & - & - & - & - & - & - \\
\hline More expensive & - & $-0.19 * *$ & $-0.32 * * *$ & $-0.15^{* *}$ & $-0.14 * *$ & $-0.22 * * *$ & $-0.26 * * *$ & $-0.23^{* * *}$ & $-0.20 * * *$ \\
\hline$F$ & $3.21 * *$ & $4.51 * * *$ & $5.94 * * *$ & $3.92 * *$ & $5.61 * * *$ & $4.46 * * *$ & $13.65^{* * *}$ & $5.26 * * *$ & $35.89 * * *$ \\
\hline$R^{2}$ & 0.036 & 0.089 & 0.143 & 0.038 & 0.054 & 0.106 & 0.065 & 0.077 & 0.045 \\
\hline Adj. $R^{2}$ & 0.025 & 0.069 & 0.119 & 0.028 & 0.044 & 0.083 & 0.06 & 0.062 & 0.044 \\
\hline
\end{tabular}

Notes: This table provides respondents' influential demographic characteristics for each of the eight categories (containing each combination of the three agent characteristics). Variables were entered into the regression using the "backward" method. Dashes indicate that a variable was removed in the final model. Tvalues omitted due to space limitations and are available upon request.

$* p<.1$

$* * p<.05$

$* * * p<.01$ 
Exhibit 2. Descriptive Statistics by Real Estate Agent Characteristic Categories

\begin{tabular}{|c|c|c|c|c|c|c|c|c|c|}
\hline \multirow{3}{*}{$\begin{array}{l}\text { Agent gender } \\
\text { Attractiveness }\end{array}$} & Cat 1 & Cat 2 & Cat 3 & Cat 4 & Cat 5 & Cat 6 & Cat 7 & Cat 8 & Combined \\
\hline & \multicolumn{2}{|c|}{$\overline{\text { Female }}$} & \multicolumn{2}{|l|}{ Male } & \multicolumn{2}{|c|}{ Female } & \multicolumn{2}{|l|}{ Male } & \\
\hline & Low & High & Low & High & Low & High & Low & High & \\
\hline Used pathos & No & No & No & No & Yes & Yes & Yes & Yes & \\
\hline Sample mean & 6.28 & 6.14 & 6.30 & 6.22 & 6.28 & 6.48 & 6.27 & 6.02 & 6.25 \\
\hline Sample size & 188 & 200 & 194 & 210 & 203 & 197 & 201 & 201 & 1594 \\
\hline Males $(N=753)$ & 6.52 & 6.09 & 6.21 & 6.16 & 6.20 & 6.59 & 6.11 & 6.10 & 6.25 \\
\hline Females $(N=833)$ & 6.11 & 6.18 & 6.37 & 6.32 & 6.36 & 6.37 & 6.41 & 5.96 & 6.25 \\
\hline Single $(N=839)$ & 6.23 & 6.07 & 6.20 & 6.08 & 6.17 & 6.42 & 6.13 & 5.95 & 6.15 \\
\hline Married $(N=749)$ & 6.34 & 6.22 & 6.45 & 6.38 & 6.39 & 6.56 & 6.41 & 6.12 & 6.36 \\
\hline College degree $(N=900)$ & 6.30 & 5.85 & 6.37 & 6.38 & 6.19 & 6.48 & 6.39 & 5.85 & 6.22 \\
\hline No degree $(N=687)$ & 6.22 & 6.51 & 6.23 & 6.06 & 6.43 & 6.48 & 6.09 & 6.24 & 6.28 \\
\hline Gay/Bisexual $(N=122)$ & 6.43 & 6.29 & 5.94 & 6.11 & 6.17 & 7.33 & 5.82 & 6.07 & 6.20 \\
\hline Not gay $(N=1,462)$ & 6.27 & 6.13 & 6.34 & 6.26 & 6.29 & 6.44 & 6.31 & 6.02 & 6.26 \\
\hline Caucasian $(N=1230)$ & 6.34 & 6.20 & 6.19 & 6.28 & 6.35 & 6.49 & 6.27 & 6.07 & 6.28 \\
\hline Non-Caucasian $(N=324)$ & 6.38 & 5.88 & 6.65 & 6.37 & 5.95 & 6.49 & 6.38 & 6.06 & 6.27 \\
\hline Black $(N=84)$ & 6.00 & 6.43 & 6.90 & 6.87 & 6.14 & 5.55 & 7.38 & 5.55 & 6.33 \\
\hline Asian $(N=129)$ & 6.71 & 5.69 & 6.94 & 5.57 & 5.08 & 7.09 & 6.08 & 6.11 & 6.16 \\
\hline Hispanic $(N=89)$ & 6.22 & 5.67 & 6.43 & 6.73 & 6.78 & 6.82 & 6.33 & 6.57 & 6.46 \\
\hline Caucasian $(N=1,230)$ & 6.34 & 6.20 & 6.19 & 6.28 & 6.35 & 6.49 & 6.27 & 6.07 & 6.28 \\
\hline
\end{tabular}

Notes: This table contains mean scores for the overall house rating for each of the eight categories (containing each combination of the three real estate agent characteristics). The table shows means for the main effects; no two-way or three-way interactions were significant. Bold numbers indicate pairs statistically significant at $p<.1$. When there are only two categories, an independent samples $t$-test is used. When there are more than two categories, ANOVA and post hoc tests are used. In both cases, a Levene statistic is first calculated to determine if it should be assumed that the variances are equal.

The Effect of Patbos. Both the highest and lowest overall impressions were elicited for attractive agents using pathos. Hence, the use of pathos does not offer a clear advantage. While it would be logical that customers with more education (i.e., college degrees) would be less influenced by pathos, this is not the case, in general. Some agents used pathos more effectively than others. For instance, the attractive female agent using pathos stimulated the most favorable home impressions. Yet, effectiveness also varied by subject group. Although the attractive female agent using pathos induced the highest overall home impressions in general, particularly among homosexual buyers (both male and female), she prompted the lowest overall home impression among Black buyers (tied with the attractive male agent using pathos). However, Black buyers were not completely put off by the use of pathos; indeed, they were influenced by pathos coming from the less attractive male agent. Therefore, the effectiveness of using pathos to attract customers depends on the agent and which buyers the agent targets. Our findings are summarized in Exhibit 3. 
Exhibit 3. Summary of Findings

\begin{tabular}{|c|c|c|c|c|}
\hline & \multicolumn{3}{|c|}{ Agent Characteristics } & \multirow{2}{*}{$\begin{array}{l}\text { Findings } \\
\text { Influence on buyer's overall house impression }\end{array}$} \\
\hline & Pathos & Gender & Attractiveness & \\
\hline 1 & None & Female & Lower & Males had a higher overall impression than female buyers. \\
\hline 2 & None & Female & Higher & $\begin{array}{l}\text { Buyers without a college degree had a higher overall impression } \\
\text { than buyers with a degree. }\end{array}$ \\
\hline 3 & None & Male & Lower & $\begin{array}{l}\text { Caucasians had lower overall impressions than non-Caucasians, } \\
\text { especially Asians. }\end{array}$ \\
\hline 4 & None & Male & Higher & $\begin{array}{l}\text { Asians had a lower overall impression than Blacks and } \\
\text { Hispanics. }\end{array}$ \\
\hline 5 & Used & Female & Lower & $\begin{array}{l}\text { Asians had a lower overall impression than Blacks and } \\
\text { Caucasians. }\end{array}$ \\
\hline 6 & Used & Female & Higher & $\begin{array}{l}\text { Blacks had a lower overall impression than other races, and } \\
\text { heterosexual subjects had a lower overall impression than } \\
\text { homosexual subjects. }\end{array}$ \\
\hline 7 & Used & Male & Lower & Subjects in all demographics had similar impressions. \\
\hline 8 & Used & Male & Higher & $\begin{array}{l}\text { Single subjects had a lower overall impression than married } \\
\text { subjects. Subjects had a higher overall impression for attractive } \\
\text { female agents using pathos than attractive females not using } \\
\text { pathos and attractive male agents using pathos. }\end{array}$ \\
\hline \multicolumn{4}{|c|}{ Overall effects } & $\begin{array}{l}\text { Also, the more people usually pay for a house, the lower their } \\
\text { overall impression. Finally, married people tended to have } \\
\text { slightly better overall impressions. }\end{array}$ \\
\hline
\end{tabular}

\section{Main Study Discussion}

Our findings offer a number of implications for real estate agents. First, our results show that targeting customers with the same demographics is not necessarily an effective marketing strategy. While it is possible that similarity between the agent and customer increases comfort in dealing with an agent once the buying process has begun (which is outside of the scope of this research), similarity between the customer and agent does not increase the overall impression of a property in online listings. If anything, the opposite is true; minority subjects were sometimes more influenced than the Caucasian subjects by the Caucasian real estate agents used in this research. Therefore, agents posting their photographs may find that they attract customers of other races.

Also, agent attractiveness does not entice customers in a way that is consistent with the customer's sexual interest. There was no significant difference by gender or marital status. One might think that attractive female agents targeting single heterosexual men would elicit a halo effect. However, men's overall house impressions were not consistently influenced by the attractiveness of the female agent. Instead, the less attractive female agent not using pathos generated a higher home impression from males than did the attractive female agents not using pathos. In fact, the attractive female agent using pathos influenced the house impression of homosexual subjects more than heterosexual buyers for both males and females. Hence, although attractiveness is important, the halo effect on the property evaluation does not appear to be based on sexual interest. 
Additionally, the effectiveness of pathos was complex. An agent's use of pathos influenced some subjects positively and others negatively. Consistent with Friestad and Wright (1994), we speculate that some customers feel less comfortable hearing pathos from certain agents. Customers likely make stereotypical inferences about agents and their motives based on salient characteristics, such as appearance. Customers who are suspicious of an agent's motives may consider the use of pathos to be self-serving while customers who are less suspicious of an agent's motives should be more susceptible to pathos. For example, many subjects reacted negatively when the attractive male real estate agent used pathos, particularly married subjects. Therefore, the decision of whether to use pathos or not should not be made lightly. The results of this study can be used to help inform agents' decisions to use pathos, and it might also be a good idea for agents to talk to a few members of their target market.

Finally, it is important to reiterate that segmentation strategies for attracting buyers is separate from personal selling strategies for assisting customers once contact is made. Because customers within a segment tend to have somewhat related opinions as a group, target marketing can help agents customize advertisements to potential customers the agent has not yet met. However, once an agent makes contact with someone, the agent should not assume that this individual would have the same opinions as their group. There is substantial variation among people of the same group so making stereotypical assumptions about buyers, instead of talking to them, will almost certainly be viewed negatively. Once contact is made with a potential customer, the agents should use best practices in personal selling, which include adapting selling behaviors based on their preferences and being customer oriented (Franke and Park, 2006).

\section{Post Hoc Analysis-Room by Room}

During an informal interview with a local real estate agent, the agent repeatedly claimed that "women buy kitchens, bedrooms, and bathrooms, and men buy yards and man caves (e.g., garages, basements, and unfinished rooms)." This agent's opinion reflects the perception that there is a gender association with certain parts of the house. Even though everyone must sleep and use the bathroom, and cooking and gardening are common activities among both genders, people may stereotypically associate a particular gender with certain rooms. Research has shown many associations between gender and objects, such as likelihood to play a certain instrument in school (Abeles, 2009), color preference (Pomerleau, Bolduc, Malcuit, and Cossette, 1990), and inclination towards playing with children's toys (Serbin et al., 2001). For example, male agents may be stereotypically associated with outdoor spaces, female agents may be stereotypically associated with kitchens or bedrooms, and attractive agents may be associated with curb appeal. Therefore, we argue that agents may be stereotypically associated with certain housing features.

Even pathos may be seen as more appropriate when showing certain parts of the house, (e.g., curb appeal), but less appropriate for other parts of the house (e.g., kitchen). It is possible that agents with stereotypically congruent niches may be viewed differently than agents with stereotypically incongruent niches. However, to our knowledge, no studies 
Exhibit 4. Pathos by Agent Characteristics and Room in the House

\begin{tabular}{|c|c|c|c|c|c|c|c|c|c|}
\hline \# of Words & Characteristic & Overall & Men & Women & $\begin{array}{l}\text { Attractive } \\
\text { Men }\end{array}$ & $\begin{array}{l}\text { Attractive } \\
\text { Women }\end{array}$ & $\begin{array}{l}\text { Unattractive } \\
\text { Men }\end{array}$ & $\begin{array}{l}\text { Unattractive } \\
\text { Women }\end{array}$ & \\
\hline & & $N=$ & 1,590 & 804 & 786 & 410 & 396 & 394 & 390 \\
\hline & House Rating & Positive & 6.26 & 6.15 & 6.38 & 6.02 & 6.48 & 6.27 & 6.28 \\
\hline & & Neutral & 6.23 & 6.26 & 6.21 & 6.22 & 6.14 & 6.30 & 6.28 \\
\hline \multirow[t]{2}{*}{8} & Kitchen & Positive & 5.00 & 5.06 & 4.93 & 5.08 & 5.03 & 5.05 & 4.85 \\
\hline & & Neutral & 5.07 & 5.00 & 5.15 & 4.92 & 5.22 & 5.08 & 5.07 \\
\hline \multirow[t]{2}{*}{7} & Curb Appeal & Positive & 6.22 & 6.09 & 6.35 & 6.13 & 6.43 & 6.05 & 6.27 \\
\hline & & Neutral & 6.22 & 6.25 & 6.19 & 6.26 & 6.16 & 6.23 & 6.23 \\
\hline \multirow[t]{2}{*}{6} & View/Back Yard & Positive & 7.14 & 7.06 & 7.21 & 6.99 & 7.29 & 7.14 & 7.14 \\
\hline & & Neutral & 6.98 & 7.00 & 6.96 & 7.02 & 6.98 & 6.97 & 6.94 \\
\hline \multirow[t]{2}{*}{5} & Master Bedroom & Positive & 5.58 & 5.55 & 5.61 & 5.44 & 5.68 & 5.66 & 5.55 \\
\hline & & Neutral & 5.59 & 5.55 & 5.64 & 5.54 & 5.59 & 5.56 & 5.69 \\
\hline \multirow[t]{2}{*}{3} & Main Living Area & Positive & 5.10 & 5.05 & 5.14 & 5.00 & 5.17 & 5.11 & 5.11 \\
\hline & & Neutral & 5.00 & 4.93 & 5.08 & 4.97 & 5.07 & 4.89 & 5.08 \\
\hline \multirow[t]{2}{*}{2} & Master Bathroom & Positive & 4.59 & 4.64 & 4.53 & 4.56 & 4.65 & 4.73 & 4.41 \\
\hline & & Neutral & 4.50 & 4.48 & 4.52 & 4.46 & 4.45 & 4.49 & 4.60 \\
\hline
\end{tabular}

Notes: \# of Words is the number of pathos words that are heard during the property (or room) description. \% of Words is the number of Pathos words divided by the total number of words that are heard during the property (or room) description. Ex ante Ranking reflects the order in which each room is expected to be able to receive a higher rating through pathos. This ranking is based on a combination of \# of Words and \% of Words. Numbers in bold indicate statistically significant differences at a minimum of $10 \%$ based on a Levene test for homogeneity of variance followed by a corresponding independent samples $t$-test. 
have looked at whether female and male real estate agents are associated with certain rooms in the house.

The home tour contains six still photographs that are shown while the agent verbally describes the property. In Exhibit 4, we show room ratings by agent. The female agents were more able to influence the "view/back yard" photo using pathos than males, particularly the attractive female agent. This is important because the curb appeal photo is the first picture homebuyers typically see whether in person or on the Internet. This finding may explain why the attractive female agent using pathos, was most able to influence the subjects impression of the overall house. As in other areas of life, first impressions appear to matter. Conversely, female agents using pathos in the kitchen resulted in significantly lower kitchen ratings than females not using pathos. While not significantly different, it is worth noting that the ratings are in the exact opposite direction for male agents. The results taken together may mean that customers do associate agent gender with certain rooms, and rather than being an advantage, it causes customers to be more vigilant of pathos.

\section{Limitations and Directions for Future Research}

The findings show that customers' overall house impressions can be influenced by the real estate agent's physical characteristics and use of pathos. Nevertheless, this research does have several limitations, which offer directions for future research. First, we investigated the effect of agent characteristics on overall home impressions in online listings for the purpose of attracting customers. It is possible that agent characteristics may influence these individuals differently once face-to-face contact has begun.

Another limitation is that we focused on one dependent variable, overall home impression. Although overall home impression is critical for motivating buyers to make first contact, agent characteristics and use of pathos might influence customer perceptions in a number of other ways, such as perceived trust, expertise, and comfort working with an agent. It is possible that a customer could contact an agent and ask to see other available properties.

Finally, while it is clear that some groups of customers are more influenced by certain real estate agents than others, the advantage in some cases was small. Hence, our findings support the argument that targeting specific customer niches can be an effective strategy for attracting customers, but those targeting strategies do not necessarily have to be aligned with the real estate agent's demographic characteristics. Future research should examine other target marketing strategies for real estate agents.

\section{Endnote}

${ }^{1}$ We conducted pretests of the male voice conditions using 34 undergraduate students attending a large mid-Atlantic university and seven other people. Pretest respondents were asked the gender of the speaker and all respondents identified the speaker as male; none recognized that the voice had been modified. 


\section{References}

Abeles, H. Are Musical Instrument Gender Associations Changing? Journal of Research in Music Education, 2009, 57:2, 127-39.

Andreoni, J. and R. Petrie. Beauty, Gender, and Stereotypes: Evidence from Laboratory Experiments. Journal of Economic Psychology, 2008, 29:1, 73-93.

Aristotle. Rhetoric. Nichomachean Ethics. In Aristotle in 23 Volumes. Rackman translation. Cambridge: Harvard University Press, 1934.

Bower, A. and S. Landreth. Is Beauty Best? Highly Versus Normally Attractive Models in Advertising. Journal of Advertising, 2001, 30:1, 1-12.

Brown, J.J. and P.H. Reingen. Social Ties and Word-of-Mouth Referral Behavior. Journal of Consumer Research, 1987, 14:3, 350-62.

Cialdini, R. Influence. Fifth edition. Boston, MA: Pearson, 2009.

Eckel, C. and R. Wilson. Detecting Trustworthiness: Does Beauty Confound Intuition? Working paper. Virginia Polytechnic Institute and State University, 2003.

Evans, K.R., R.E. Kleine Ill, T.D. Landry, and L.A. Crosby. How First Impressions of a Customer Impact Effectiveness in an Initial Sales Encounter. Journal of the Academy of Marketing Science, 2000, 28:4, 512-26.

Friestad, M. and P. Wright. The Persuasion Knowledge Model: How People Cope with Persuasion Attempts. Journal of Consumer Research, 1994, June 21, 1-31.

Franke, G.R. and J.E. Park. Salesperson Adaptive Selling Behavior and Customer Orientation: A Meta-Analysis. Journal of Marketing Research, 2006, 43:4, 693-702.

Goodwin, K., B. Waller, and S. Weeks. The Impact of Broker Vernacular in Residential Real Estate. Journal of Housing Research, 2014, 23:2, 143-61.

Haag, J., R. Rutherford, and T. Thomson. Real Estate Agent Remarks: Help or Hype? Journal of Real Estate Research, 2000, 20:1/2, 205-15.

Johnson, D.M. and R.N. Vidulich. Experimental Manipulation of the Halo Effect. Journal of Applied Psychology, 1956, 40:2, 130.

Lovelock, C.H. Classifying Services to Gain Strategic Marketing Insights. The Journal of Marketing, 1983, 47, 9-20.

Lucker, G.W., W.E. Beane, and R.L. Helmreich. The Strength of the Halo Effect in Physical Attractiveness Research. The Journal of Psychology, 1981, 107:1, 69-75.

McPherson, M., L. Smith-Lovin, and J. Cook. Birds of a Feather: Homophily in Social Networks. Annual Review of Sociology, 2001, 27, 415-44.

Mobius, M. and T. Rosenblat. Why Beauty Matters. American Economic Review, 2006, 96:1, 222-35.

Morrow, P. Physical Attractiveness and Selection Decision Making. Journal of Management, 1990, 16:1, 45-60.

Nisbett, R.E. and T.D. Wilson. The Halo Effect: Evidence for Unconscious Alteration of Judgments. Journal of Personality and Social Psychology, 1977, 35:4, 250.

Patzer, G. The Physical Attractiveness Phenomena. New York City, NY: Plenum Press, 1985. Plato. Laws. In Plato in Twelve Volumes. Vol. 11. Bury translator. Cambridge: Harvard University Press, 1968.

Pomerleau, A., D. Bolduc, G. Malcuit, and L. Cossette. Pink or Blue: Environmental Gender Stereotypes in the First Two Years of Life. Sex Roles, 1990, 22:5-6, 359-67.

Pryce, G. and S. Oates. Rhetoric in the Language of Real Estate Marketing. Housing Studies, 2008, 23:2, 319-48.

Ravina, E. Beauty, Personal Characteristics and Trust in Credit Markets. Working paper. New York City, NY: Columbia University, 2011. 
Salter, S.P., F.G. Mixon Jr., and E.W. King. Broker Beauty and Boon: A Study of Physical Attractiveness and its Effect on Real Estate Brokers' Income and Productivity. Applied Financial Economics, 2012, 22:10, 811-25.

Schneider, D.J. The Psychology of Stereotyping. Guilford Press. 2005.

Serbin, L.A., D. Poulin-Dubois, K.A. Colburne, M.G. Sen, and J.A. Eichstedt. Gender Stereotyping in Infancy: Visual Preferences for and Knowledge of Gender-Stereotyped Toys in the Second Year. International Journal of Bebavioral Development, 2001, 25:1, 7-15.

Smith, N.C. and E. Cooper-Martin. Ethics and Target Marketing: The Role of Product Harm and Consumer Vulnerability. Journal of Marketing, 1997, 61, 1-20.

Smith, S.J., M. Munro, and H. Christie. Performing (Housing) Markets. Urban Studies, 2006, 43:1, 81-98.

Springer, T.M. Single-family Housing Transactions: Seller Motivations, Price, and Marketing Time. The Journal of Real Estate Finance and Economics, 1996, 13:3, 237-54.

Aaron Arndt, Old Dominion University, Norfolk, VA 23529-0223 or aarndt@odu.edu. David M. Harrison, University of Central Florida, Orlando, FL 32816 or David.Harrison2@ ucf.edu.

Mark A. Lane, Old Dominion University, Norfolk, VA 23529-0223 or malane@odu.edu. Michael J. Seiler, College of William \& Mary, Williamsburg, VA 23185 or Michael.Seiler@ mason.wm.edu.

Vicky L. Seiler, Norfolk, VA 23508 or drvickyseiler@gmail.com. 